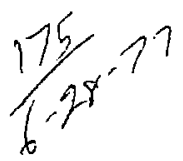

A. 1165

\title{
SHIELDING OF MIRROR FERF PLASMA BY ARC DISCHARGES
}

\author{
J. T. Woo
}

December 8, 1976

Prepared for U.S. Energy Research \& Development Administration under contract No. W-7405-Eng-48

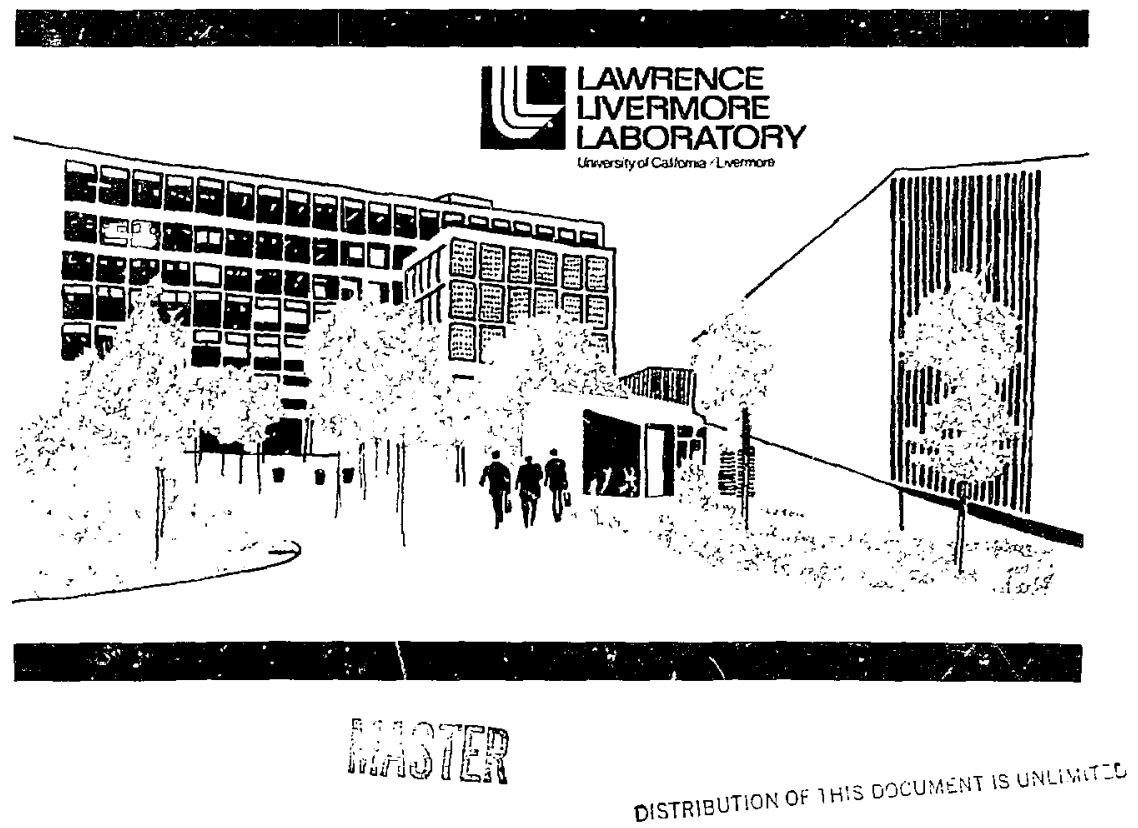




\section{NOTCE}

This report wa prepared os an acousat of woth sponsor: $J$ by the Unied Sutes Govemunent. Neither the United Sutes nor tha United States Energy Rexirh 2. Developrneat Admbartition, an any of their

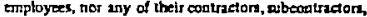
or their employees, maken eny warercy, exprea a implied, of essumen any legal liability or repponsibility for the acouracy, completences of usefulness of any information, apparetus, produce or process diselosed, or represents that its $u$ w wauld not infinge priratelyowred rights.

\section{NOTICE}

Feference to a company or product name does not imply opproval of reconmendation of the produa by the Univervity of Californil or the US. Energy Research \& Dereloptrear ndmintsurtion to the exdustion of others that mry be suitable.

Pronted in the Unjied Siztes of Arneng Arailable from

Notional Technogl Informatton Servix

US. Department of Commerce

5285 Port Royal Rosd

Springrield, VA 22161

Pnce: Pnnted Copy 5 . Nicruficte $\$ 3.00$

\begin{tabular}{|c|c|c|c|}
\hline Pasa Ranga & $\begin{array}{l}\text { Domestic } \\
\text { Price }\end{array}$ & Pusp Runge & $\begin{array}{c}\text { Domertic } \\
\text { Priso }\end{array}$ \\
\hline $001-025$ & 33.50 & $\begin{array}{l}326-350 \\
351-375\end{array}$ & 10.00 \\
\hline $\begin{array}{l}026-050 \\
051-075\end{array}$ & $\begin{array}{l}4.00 \\
4.50\end{array}$ & $\begin{array}{l}351-375 \\
376-400\end{array}$ & $\begin{array}{l}10.50 \\
10.75\end{array}$ \\
\hline $076-100$ & 5.00 & $401-+25$ & 1100 \\
\hline $101-125$ & 5.50 & $426+50$ & 11.75 \\
\hline $126-150$ & 6.00 & $451-475$ & 12.00 \\
\hline $151-175$ & 6.75 & $\$ 76-500$ & 12.50 \\
\hline $176-200$ & 7.50 & $50 \mathrm{l}-525$ & 12.75 \\
\hline $201-225$ & 7.75 & $526-550$ & 13.00 \\
\hline $2=6-250$ & 8.00 & $551-575$ & 13.50 \\
\hline $251-275$ & 9.00 & $576 \leqslant 00$ & 13.75 \\
\hline $276-300$ & 9.25 & $601-4 p$ & 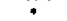 \\
\hline $301-325$ & 9.75 & & \\
\hline
\end{tabular}

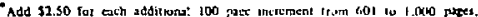
add $\$ 4.30$ for esch additioral 100 pape incterient oner 1,000 grots. 


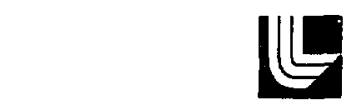

\section{LAWRENCE LIVERMORE LABORATORY}

University ol Cahtomia Livermore, Calfoma 94550

UCRL-52181

\section{SHIELDING OF MIRROR FERF PLASMA BY ARC DISCHARGES}

MS. date: December 8, 1976

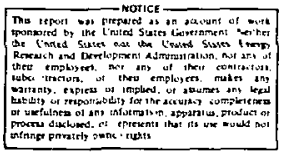




\title{
SHIELDING OF MIRROR FERF PLASMA BY ARC DISCHARGES
}

\begin{abstract}
We have investigated the feasi-

ments for the plasma blanket are bility of shielding a mirror-confined dependent on the parameter $\gamma$, the fusion plasma against erosion by Incident neutrals with a plasma blanket generated by an array of hollowcathode arc discharges. Such a plasma blanket could also be used for linerat lo of the actual cross-field diffusion coefficlent to the classical value. T e power requirement compares fav ably with power loss due to change exchange without shielding. tying stabilization of a single mirror confined plasma as we11 as to provide: a warm plasma stream for stabllization of microlnstabilitles. The requireMore Importantly, the blanket permits a relaxation of vacuum requirements to prevent erosion of the hot plasma by background neutrals.
\end{abstract}

\section{Introduction}

It is well known that if a mirrorconfined plasma is sustalned at high density by energetic neitral Injection, all the background neutrals will be attenuated at the plasma surface. Because of charge exchange, the attenuation of the background neutrals represents an additional loss of hot lons from the plasma. The condition required to sustain the plasma surface against erosion and hence to mafntin the bulk plasma in steady state has been considered by Fowler. I Fowler has shown that a sufficient condition requires that the race of trapping the infected energetic neutrals at the plasma surface over a mixing length (on the order of an ion gyroradius) equal the charge exchange loss rate. The energetic particles trapped at the plasma surface are thus sacriEiced to shield the bulk plasma. Charge exchange results in the emission of energetic neutrals by the plasma and is energetically costly as well as damaging to the first-wall material. It is therefore desirable to devise a suicable means to prevent 
the hot plasma from interacting with the background neutrals. A possible approach is to surround the fusion plasma with a low-temperature high-dens1ty blanket plasma generated by arc wischarge. ${ }^{2}$ we con- sider the feasibility of this approach as well as typical destgn parameters for incorporating this method into the mirror Fusion Engineering Research Facility (FERF). ${ }^{3}$

\section{Plasma Blanket Concept}

The configuration of the mirror FERF is shown in Fig. 1 and the relevant parameters are 1 isted below.

- Center field $B_{0}=37.5 \mathrm{kG}$.

- Vacuum mirror ratio $\mathrm{R}=2$.

- Vacuum radfal we11-shape is essentially flat.

- Field at end wall $=0.4 \mathrm{~B}_{0}$.

- Center plasma density $=3 \times 10^{14}$ $\mathrm{cm}^{-3}$.

- Density profile $n(r)$ $=n_{0}\left[1-(r / 25)^{3}\right]$.

- Injection energy $=65 \mathrm{keV}$. We conzider the arrangement of a series of reflex arcs around the fish tail of the fanning magnetic field lines located beyond the mirror throat on flux lines adjacent to the first wal1. The arc discharge will tend to stream freely along the flux Iines aud to drift transversly to both the flux lines and the fleld-line curvature. Thus, it will form a blanket around the volume concaining the hot plasma while diffusing slowly outward, toward the wall and inward, coward the bulk plasma. Given a suitable plasma source, the basic requirement for establishing such a plasma blanket is that the collisiona? scattering time be short compared to the average lifetime of the fons in the plasma. This condition generally is well satisfled in high-density, lowtemperature plasma typical of arc discharges. The crictcal questions. therefore, concern the source requirements, gas load, and power consumption. It is obvious that the discharge plasma must essentially be fully lonized. It is also desirable that both the power and gas efflciency for the system (which aust operate in steady state) be filgn. 1t.e hollowcatiode discharge (HCD) has been applied previously to feed highdenstty flasma coluuns in steady state of several meters in length ${ }^{4}$, it appears to be well suited to chis application. Therefore, our first concern is to establish the sor paibility of HCD parameters from a ingle source with the requirements for effective shielding. We then consider a 


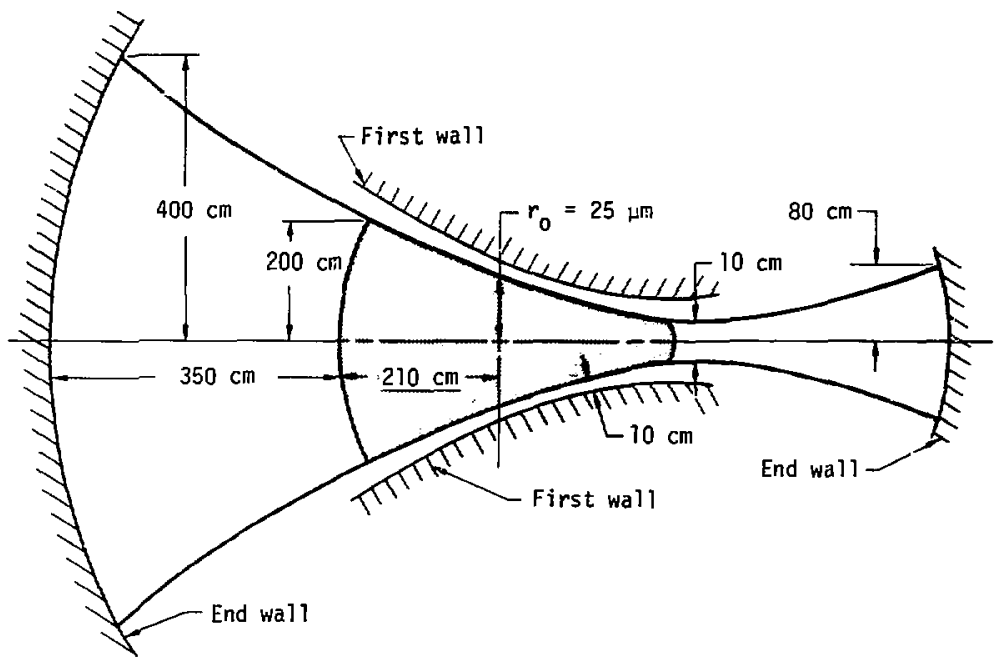

F1g. 1. Characteristic dimenslons of the Mirror Fusion Engineering Research Facility.

possible design of a system to provide an effective plasma blanket for shielding against erosion by the background neutrals.

\section{Hollow Cathode Discharge Source}

For effective shielding, the plasma blanket must be opaque to the Incident background neutrals of velocity $v_{0}$, such that

$$
\frac{\langle\sigma v\rangle}{v_{0}} \int \text { nd } \ell>1,
$$

where $\langle\sigma v\rangle$ is the reaction rate averaged over the distribution of the plasma and the integral is across the thickness of the plasma blanket. For conditions typical of discharge plasmas $\left(T_{e} \simeq 10\right.$ to $\left.100 \mathrm{eV}, T_{i} \leq 1 \mathrm{eV}\right)$, attenuation occurs primarily by electron forlation. The reaction rate parameter for a Maxwellian plasma is shown in Fig. 2. 5 The rate of reaction peaks at $100 \mathrm{eV}$, representing an optimum electron temperature in the discharge for shielding. 


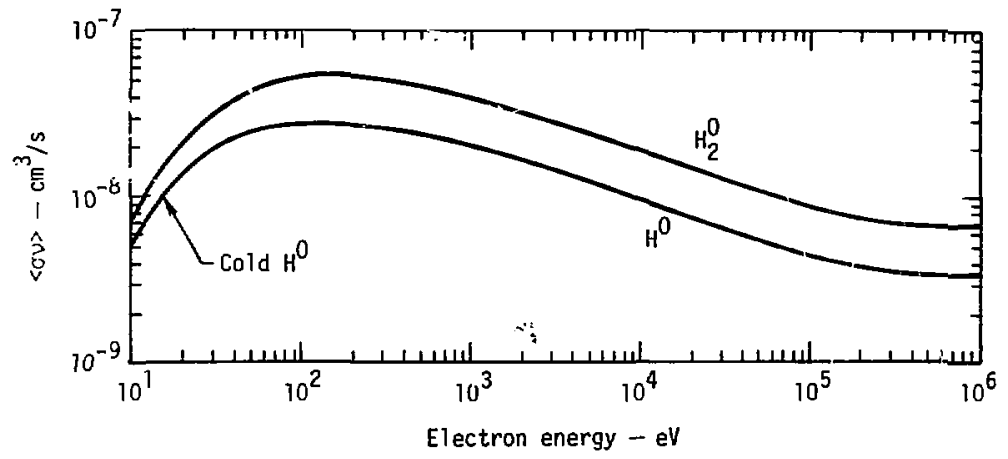

Fig. 2. Ionfzation rate for Maxwellian electrons.

To determine the source requirements, we must consider the dynamics of the discharge in a strong axial magnetic field. For typical arc discharge conditions, the conductivity along the field lines is high and thus, the plasma generated in the hollow cathode will stram along the flux line. The like-particle scattering time is very short: $\tau_{i 1} \leqslant 10^{-8}$ to $10^{-6} \mathrm{~s}$. Consequent $1 \mathrm{y}$, the mirror fleld has virtually no effect on axial distribution of the plasina column. Ions recurning to the cathode along the flux lines are recycled while those that are scattered across the field lines feed the external plasma to form the blanket. For HCDs arranged in the reflex mode, the external plasma column is generally found to be space-charge negative because radial diffusion of the ions Is that dominant loss mechantam. The spatial-densicy distribution in this case can then be described by tine radial diffusion equation for the lons,

$$
\frac{\partial n}{\partial t}+D \frac{\partial}{\partial r}\left(r \frac{\partial n}{\partial r}\right)=0,
$$

where $D$ is the effective, cross:field diffusion coetricient that Ircludes turbulence and acbipolar-end effects.

The steady-state solution for the boundary conditions there the density vanishes at a radius $r=a$ is

$$
\mathrm{n}=-\frac{\mathrm{Q}}{2-\mathrm{D}} \ln \frac{\overline{\bar{a}}}{\mathrm{a}} \text {, }
$$

where $Q$ is the line-scurce condition per unit lengeh of the external discharge. For effective shielding 
by the plasma that is produced by a thin-line source of radius $\delta$ diffusing radially, the required conditions according to Eq. (1) are:

$$
\begin{aligned}
\lim _{\delta \rightarrow 0} \int_{\delta}^{a} \mathrm{nd} \ell & =\int_{\delta}^{a}-\frac{Q}{2 \pi D} \ln \frac{\Gamma}{\mathrm{a}} \mathrm{d} r, \\
& =-\frac{Q \mathrm{a}}{2 \pi D}\left[-\frac{\delta}{\mathrm{a}} \ln \frac{\delta}{\mathrm{a}}-1+\frac{\delta}{\mathrm{a}}\right], \\
& \simeq \frac{Q \mathrm{a}}{2 \pi D} \geq \frac{v_{0}}{\langle\sigma \mathrm{v}\rangle} .
\end{aligned}
$$

The effectiveness of the plasma blanket and the requirements of the source condition are inversaly proporthonal to the effective transverse diffusion coefflcient. vifiusion across the magnetic field in arc columns is strongly affected by the operating and bounda: y conditions. This is evident from the above discussion and is also considered extensively in Refs. (6-8). If the plasma 15 Eully lonized, classical diffuston arlses from electron-1on collistons. The transverse diffusion crefficient. for a fluid plasma in a uniform magnetic field $B$ and with internal energy $k T$ is given by

$$
D=\frac{n k T}{B^{2}} \eta,
$$

where $r=\left(1.6 \times 10^{-9} \mathrm{z}\right) \ln \Lambda / \mathrm{T}_{\mathrm{e}} \mathrm{e}^{3 / 2} \Omega \cdot \mathrm{m}$ is the Spltar resistivity and $T_{e}$ is expressed in kev. End effects and large scale oscillations tend to entance the effective cross-field diffusion coefficient to values that lie between the classical value and the empirical Bohm rate:

$$
\mathrm{D}_{\text {Bohm }} \simeq \frac{1}{16} \frac{\mathrm{kT}}{\mathrm{qB}^{\mathrm{B}}} .
$$

It has been shown that, under sultable conditions, the transport in a fully ionfzed, long plasma columo can be accounted for by classical processes. 9 Typically, an arc colum greater than 2 m In lengtt has been sustained In magnetlc flelds of a few kflogauss and with a line density of $2 \int_{0}^{a} n d r=10^{14} \mathrm{~cm}^{-2}$ hy a gas feed of $0.1 \mathrm{~atm} \cdot \mathrm{c}^{\prime} 3^{3} / \mathrm{s}\left(3 \times 10^{18} \mathrm{atcm} / \mathrm{s}\right)$. The plasma is generated within the hollow cathode where the gas feed maintairis a localized condition that is sultable for the cperation of a tigh-current discharge. 10 The comparatively higher efficiency of the HCD arises from a trapping of positive lons and metastables inside the hollow cathode so that their energy is substantall? recycled. The plasma formed in the cathode is then ariven out by the pressure gradlent and, in the pressure oi an axla $a_{+}$magnetic field, this cathode plasma feeds the confired plasma colunin. The V-I characteristic of the discharge generally depends on the speciflc configurations of the electrodes. Typically, the gas is filly lonized with an energy requirement of a few hundred eiectrcr. volts per particle. The electrons, when falling over the cathode shearh and upon thernalization, have temperature 
$T_{e}$ of several cens of electron volts while the ions 1 is with a $T_{j}=1 \mathrm{eV}$.

The classical cross-fleld difusion coefficient for these typical operating conditions can be caiculated from Eq. (5) to be about $10^{-3} \mathrm{~m}^{2} / \mathrm{s}$. Substituting this into Eq. (4) for a line density of $10^{14} \mathrm{~cm}^{-2}$, the required source feed is approximatily $10^{18} \mathrm{~s}^{-1} \cdot \mathrm{m}^{-1}$, a value which is consistent with the operating condftion of the quiescent arc colum. Typical ranges of $\mathrm{HCD}$ operating parameters $a^{*} \geq$ shown below.

- Cathode inside diameter $=0.2$ ro $1.2 \mathrm{~cm}$.

- Gas feed $=0.0 \mathrm{~s}_{\text {to }} 2.0 \mathrm{~atm} \cdot \mathrm{cm}^{3} / \mathrm{s}$.

- Magnetic field $=100$ to $3000 \mathrm{G}$.

- Arc voltage $=10$ to $100 \mathrm{~V}$.

- Arc current $=10$ to $200 \mathrm{~A}$.

- Árc power $=1$ to $3 \mathrm{~kW}$.

- Center density $=10^{13}$ to $10^{14} \mathrm{~cm}^{-3}$.

- Electron temperature = several to tens of electron volts.

To form a plasma blanket to shield the FERF plasma, the operating ma.jnatic-field intensity is significantly hfgher than most pr'svious HCD operations. Classical scaling implies a reduction of the source and hence, a ciecrease $1 n$ arc-power requirements as $\mathrm{B}^{2}$, providing that the cathode conflguration is scaled accordingiy to meet the operating condition of the arc. Theoretically, ve expect that transport in a fully ionized linear plasma column will be classical. However, in addition to end effects which become more 1;uportant at ligher confi..terest flelds, the field-1ine curvature of the minlmum-B geobetry could descroy hoth equilibrim and stabil1ty. As an upper bound on the source requirements, we might postulate Bohm diffusion which would erhance the loss rat: $y$ the actor

$$
\begin{aligned}
\frac{D_{\text {Bohm }}}{D_{\text {class..cal }}}=\frac{\frac{1}{16} \frac{k T}{q B}}{\frac{B^{2}}{2}}, \\
=\frac{1}{16} \frac{\omega_{e}}{\nu_{e 1}},
\end{aligned}
$$

where $\omega_{e}$ is the electron cyclotron frequency and $v_{e i}$ is the electron-ion scattering frequency. For typical HCD parameters in an FERF field, we $\approx 2 \times 10^{11} \mathrm{~s}^{-1}$ and $v_{\mathrm{ei}}=7 \times 10^{6} \mathrm{~s}^{-1}$. Hence, the loss-rate enhancement factor is about $3 \times 10^{3}$. To estimate the source requirement, we define $\gamma$,

$$
\gamma=\frac{D_{\text {actual }}}{D_{\text {classical }}},
$$

as the ratio of the governing effective cross-field diffusion coerficient to the classical value, bearing in mind that Bohm-like diffusion corresponds to an enhancement of approximately $10^{4}$. The actual source reguirement can then be scaled by the enhancement fazcor $Y$ from the estimates based on classical diffusion. 


\section{Source Requirements}

it ahiald the mitror FERF plasma against background neutrals that arise primarily from the neutralizer cell, we assume that the "eutrals have a thurmal velocity of $10^{5} \mathrm{~cm} / \mathrm{s}$. Referring to Fig. 2, the reaction rate for innization by electrons in the 10 - to loo-eV range is several times $10^{-8} \mathrm{~cm}^{-3} / \mathrm{s}$. According to Eq. ( 4 ), the line-density requirements of the plasma blankel must be in the range of $10^{13} \mathrm{~cm}^{-2}$. For the FERF design shomn in Fip. 1, the furion plasma is isolated at a distance of $10 \mathrm{~cm}$ from the vacuum wall. Therefore, the flasma blanket must be Iimited to a thickness of a few centimeters. Currespondingiy, the average density in the central core of the plasma blarker should be approximately $n_{0}=10^{13} \mathrm{~cm}^{-3}$. Such. central density value is typical of HCD operations. The magnet.c field in the FERF end-region is $15 \mathrm{kG}$, rising to $75 \mathrm{kG}$ in the mirror throat in a distance of $3.5 \mathrm{~m}$, and then dropping in $2 \mathrm{~m}$ to a center field of $37.5 \mathrm{kG}$. The scatcering mean-free-path for the ions,

$\lambda_{i}=\frac{v_{i}}{v_{i i}}=\frac{v_{i}}{v_{e i}}\left(\frac{m_{i}}{m_{e}}\right)^{1 / 2}=0.1 \mathrm{~m}$

is much less than the characteristic distance of the syster, assuring: good communication between the end regions and tine mirror incerior. The classlcal cross-field diffusion coefficlent for these parameters (i.e., $n=10^{13} \mathrm{~cm}^{-3}, T_{e}=10 \mathrm{ei}^{i}, 3=15 \mathrm{kG}$ ) Is found from Eq. (5) to be $\mathrm{D}_{\text {classical }}$ $=1.14 \times 10^{-4} \mathrm{~m}^{2}$ is. Substituting into Eq. (4), the source. Equirement needed to maintain the desired line density of $10^{13} \mathrm{~cm}^{-2}$ in a distance $a=2 \mathrm{~cm} \mathrm{is}$

$$
\begin{aligned}
Q & =\frac{2^{-\mu D_{1}} \int_{0}^{a_{n d i}}}{a}, \\
& =3.55 \times 10^{15} \mathrm{rs}^{-j} \cdot \mathrm{m}^{-1} .
\end{aligned}
$$

Assuming that each source ieeds a colum of $4 \mathrm{~m}$, the gas Eeed per source Is $1.4 \times 10^{16} \mathrm{~s}^{-1}$, coitresponding to $10^{-3} \mathrm{y}$ atm $\mathrm{cm}^{3} / \mathrm{s}$. To maintain the conditions required for cperation of the arc, tha insida diameter of the cathode san be aporopriately scaled.

The total number of sources required to form the plasma tlanket is determined by the Ios- race. Ine total flux is,

$$
F=2 A \Gamma_{\perp}=2 \mathrm{~A} \frac{\mathrm{Q}}{2-3}=\therefore \mathrm{O},
$$

where $A$ is the sutface area of the plasma blanket and $\vec{i}$ is the flux across the surface. T:e factcr 2 accounts for the $t w$ surfaces of the plasma blanket. Ti.. cota: stifiace area is eftimated to be approsita.el. $40 \mathrm{~m}^{2}$. Hence, 


$$
N=\frac{A}{\pi a L} \simeq 120 \text {. }
$$

The total gas feed into the system is approximately $0,1 \mathrm{Y}$ atm. $\mathrm{cm}^{3} / \mathrm{s}$ and, assuming that the energy requirement is $200 \mathrm{eV} /$ atom, the power requirement is about $50 \mathrm{Y} W$. This power requirement should be compared with charge exchange losses without shielding. For a deutertum plasma of FERF parameters, the dominant interaction with background neutrals is still by charge exchange. The power loss associated with a background neutral density $n_{0}$ is $\frac{\mathrm{n}_{0} \nu_{0}}{4} A \frac{\left\langle\sigma_{\mathrm{x}} v\right\rangle}{\langle 0 v\rangle} \varepsilon$

$$
\simeq 10^{-9} \mathrm{n}_{\mathrm{o}} \mathrm{W} \cdot \mathrm{m}^{3} / \text { particle }
$$

where $E$ is the energy of the hot plasma ion ( $65 \mathrm{keV}$ in FERF). In the absence of shielding, the background neutral density must be kept below $10^{15} \mathrm{~m}^{-3}\left(\sim 10^{-8}\right.$ Torr $)$ to prevent the erosion of the hot plasma. Even at this density, the power loss is approximately $1 \mathrm{Mh}$, which makes the power requirement for the plasma blanket appear quite favorable.

\section{Conceptual Design}

Based on the above considerations, the shielding of a hot plasma by a low-temperature plasma blanket generated by arc discharge appears feastble. The possibility of feeding a plasma in a mirror region with external sources has been demonstrated In the 2XIIB experiment ${ }^{11}$ and Anderson and Hooper ${ }^{12}$ have shown the tendancy for the discharge plasma to follow the fanning minimum-B field lines. In both cases, the discharges are highpower pulses. The HCD is better sulted for the steady state operations that are required for shielding and a conceptual design of the HCD source for the plasma blanket is shown in
FIg. 3. The electrodes are located in the end regions of the vacuum system. The cathode is an array of refractory metal tubes that have been scaled to provide the desired flow rate and are oriented along the fanning field lines. For the present application, the cathode does not need to be composed of discrete tubes and thus many variations are possible. The system is symetrical about the center of the mirror system so that the discharges are operated in the double-ended reflex configuration. Electrons bouncing between the cathodes Ionize the background neutrals that diffuse into the plasma blanket. 


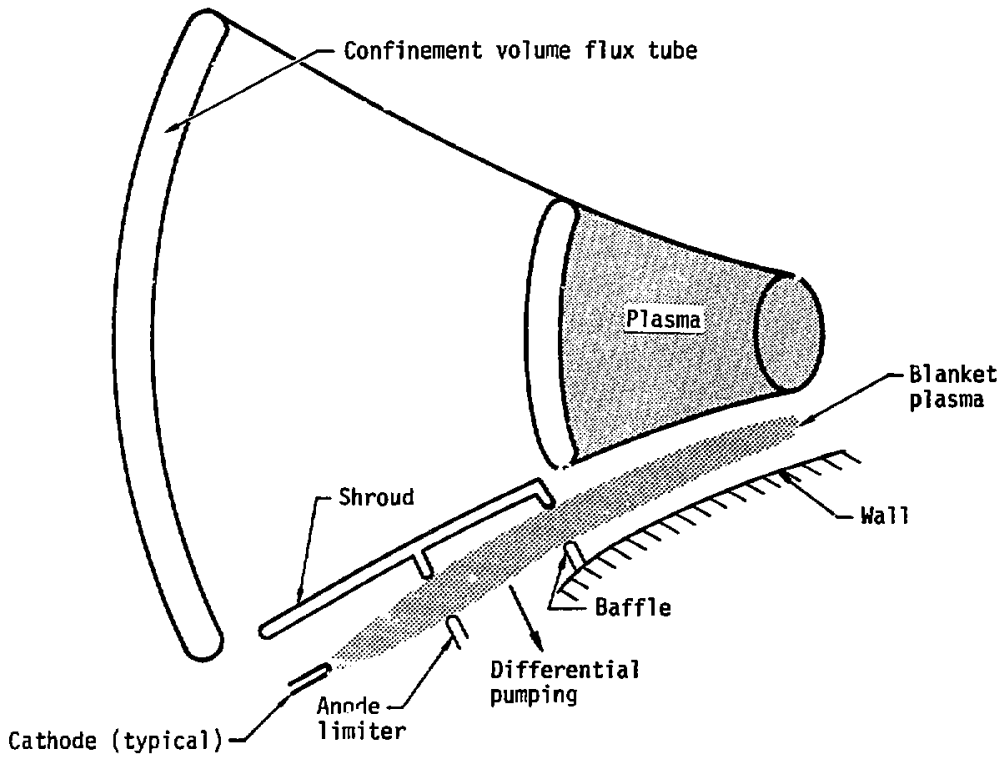

Fig. 3. Conceptual design of HCD source for a plasma blanket.

The discharge is terminated on the IImiter which serves as the anode and also defines the width of the plasma blanket. To minimize the effect of the gas feed on the vacuum condition in the confinement region, an additional baffle is installed to permit differential pumping. The density profiles for the hot fusion plasma, the cold blanket plasma, and the background neutrals are qualitatively 1llustrated in Fig. 4. The interior edge of the 1Imiter prevents intcr- mixing of the hot and cold plasmas while the plasma blanket ef iectively shields out the background neutrals.

A critical question for the feasibllity of the system is whether the the streaming gas load into the confinement region due to the arc is small comparec to the background gas In the absence of the arc. The aperture that leads to the confinement region is approximately $10^{3} \mathrm{~cm}^{2}$ in area. If we require that the background influx of neutrals into the 


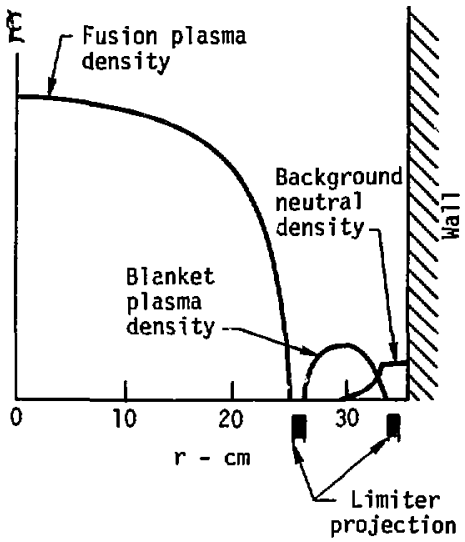

Fig. 4. Denstey profile of a fuston plasma shielded by a plasma blanket. confinement region be small (less than $10^{-3}$ ) compared to the energetic neutrals injected into the confinement region approximately $10^{22} \mathrm{~s}^{-1}$ ), the maximum permisstble denstty of neutrals in the bas: $10^{11} \mathrm{~cm}^{-3}$. This corresponds to a base pressure of $3 \times 10^{-6}$ Torr. The pumping speed required for the appropriate gas feed into the arc discharge is $10^{4} \gamma 1 / \mathrm{s}$. If $\gamma$ is much greater than unity, it is highly desirable to incorporate an additlonal differential pumping stage. However, achieving the necessary vacuum condition does not appear to pose a serlous problem.

\section{Conclusion}

The shfelding of a FERF plasma against background neutrals by the use of a plasma blanket that has been generated by hollow cathode discharge appears feasible. The requirements are estimated to be a total gas feed $\mathrm{NQ}=3 \times 10^{18} \gamma \mathrm{s}^{-1}$ and a power requirement $\mathrm{P}=50 \gamma \mathrm{W}$, where $\gamma$ is the ratio of the actual cross-fleld diffuston to classtcal diffusion in the fanned minimum-B configuration that forms the plasma blanket. The power requirement compares favorably with power loss due to change exchange in the absence of shielding. More Importantly, the blanket permits a relaxation of the severe vacuum requir mments to prevent plasma eroston by charge exchange and reduces damage to the first wall. The major questions concern the behavior of the arc colum in the fanned magnetic field configuration and can only be resolved experimentally.

It Is interesting to note that the plasma blanket is also applicable to the polotdal divertors for torotdal systens. These divertors must serve the dual function of channelling the energetic flux out of the confinement region before it can diffuse to the first wall ani, at the same tIme, ionlze and dispose of the wall-emitted impurity neutrals prevent them from 
reaching the hot plasma where they accumulate. The incorporacion of a dense plasma blanket (separated from the fuston plasma by a highty conducting, magnetic divertor channel leading out of the toroldal reactor chambers) can provide this dual function. It can minimize the energeticparticle flux to the first wall which is the cause of wal1-emitted impurities. Also, the plasma blanket wll ivalze the wall-emitted 1mpuritles so that they toc are channelled out along the diverted flux. In principle, such an arrangement can be an effective means of meeting the siringent impurity-control requirements of long-pulsed toroidal reactors.

\section{Acknowledgment}

The concept of using arc discharge to shield the mirror FERF plasma was suggested to the author by Ralph w. Moir who also provided a number of valuable coments in this invest:gat1on. 


\section{References}

1. T. K. Fowler, "Charge Exchange at the Surface of Mitror-Confined Plasmas," Plaama Phys., 17, 583 (1975).

2. R. W. Molr, Lawrence Livermore Laboratory, private communicat1on (1976).

3. T. H. Batzer, R. C. Burlelgh, G. A. Carlson, and W. L. Dexter, Conceptual Design of a Mirmor Reactor for a Eusion Engineering Research Eacility, Lawrence LIvermore Laboratory, Rept. UCRL-51617 (1974).

4. J. T. Hoo, Studies of a Highty Ionized Plasma Colwm in a Strong Magnetic Fieza, Sc.D. Thesis, Massachussetts Institute of Technology, Cambridge, Mass (1966).

5. R. Colchin, "Target Plasma Trapping," Nuct. Fus., 11, 329 (1971).

6. F. C. Hoh, "Low-Temperature Plasma Diffusion in a Magnetic Field," Rev. Mod. Phys., 34, 267 (1962).

7. W. E. Golant, "Diffusion of Charged Particles in a Plasma in a Magnetic Field," Soviet thysics Uspekhi, 6, 161 (1963).

8. F. Boeschoten, "Review of Experiments on the Diffusion of Plasma A.ross a Magnetic Field," Plasma Phys., 6, 339 (igcít).

9. J. C. Woo and D. J. Rose, "Generation of a Quiescent, Variable Parameter Arc Plasma," Phys. Fluids, 10, 893 (1967).

10. M. D. Lubin, Emission Mechanism of the Hozlow Cathode Discharge, Ph.D. thesis, Massachussetts Institute of Technology, Cambridge, Mass. (1967).

11. F. H. Coensgen, J. F. Clauser, D. L. Correll, W. F. Cunmins, C. Gormezano, B. G. Logan, A. W. Molvik, W. E. Nexsen, R. C. Stmonen, B. W. Stallard, and W. C. Turner, Status of 2XIIB PZasma Confinement Expeniments, Lawrence Livermore Laboratory, Rept. UCID-17037 (1976).

12. E. B. Hooper, Jr., and O. A. Anderson, Dense Plasma Dïacharge in Minimam-B Mirrore, Lawrence LIvermore Laboratory, Rept. UCRL-76703, Rev. 1 (1976).

PLL/1c/umc/mla 